Departamento de Historia

Universidad de Santiago de Chile

Revista de Historia Social

y de las Mentalidades

Volumen 24, $\mathrm{N}^{\circ}$ 2, 2020: 121-148

Issn Online: 0719-4749

\title{
EL INTENTO DE COPAMIENTO DE LA TABLADA (1989). REPRESIÓN, JUSTICIA Y DERECHOS HUMANOS*
}

\author{
THE ATTEMPT TO TAKE LA TABLADA (1989). \\ REPRESSION, JUSTICE AND HUMAN RIGHTS \\ DRA. MARIANELA SCOCCO** \\ Universidad Nacional de Rosario, Investigaciones Socio-históricas Regionales, \\ Consejo Nacional de Investigaciones Científicas y Técnicas \\ Rosario, Argentina \\ Email: maria_nob4@hotmail.com \\ Id-ORCID: 0000-0002-1309-1613
}

\begin{abstract}
RESUMEN
El 23 de enero de 1989, militantes de la agrupación Movimiento Todos por la Patria (MTP) encabezados por Enrique Gorriarán Merlo, intentaron copar los cuarteles del Regimiento de Infantería Mecanizada 3 "General Belgrano" en la localidad argentina de La Tablada, con el supuesto propósito de frustrar un golpe militar carapintada en contra del gobierno de Raúl Alfonsín, quien había enfrentado tres levantamientos militares a lo largo de su gestión. La represión fue desmedida y violenta y dejó varias personas heridas, muertas y desaparecidas. Este artículo se propone analizar las lecturas del ataque a La Tablada y el derrotero de la justicia al respecto, poniendo énfasis en las violaciones a los derechos humanos
\end{abstract}

\begin{abstract}
On January 23, 1989, militants of the Movimiento Todos por la Patria (MTP) group headed by Enrique Gorriarán Merlo, attempted to cover the barracks of the Mechanized Infantry Regiment 3 "General Belgrano" in the Argentine town of La Tablada, with the alleged purpose of thwarting a military coup against the government of Raúl Alfonsín, who had faced three military uprisings throughout his administration. The repression was excessive and violent and left several people injured, dead and disappeared. This article proposes to analyze the readings of the attack on La Tablada and the course of justice in this regard, emphasizing the violations of human
\end{abstract}

* $\quad$ Recibido: 11 de mayo de 2020; Aprobado: 7 de julio de 2020.

** Artículo de revisión. Esta contribución proviene de una investigación posdoctoral en curso orientada a las reformas en las bases normativas del Estado en materia de seguridad en la posdictadura. Agradezco los comentarios y sugerencias de los revisores que contribuyeron a mejorar sustancialmente el artículo. 
producidas, el rol del Estado, las consecuencias

en la modificación de las leyes represivas y el cambio en la correlación de fuerzas en la relación gobiernos/militares.

Palabras clave: Copamiento; levantamientos militares; represión; justicia; derechos humanos rights produced, the role of the State, the consequences in the modification of repressive laws and change in the correlation of forces in the governments / military relationship.

Keywords: Taking; Military uprisings; Repression; Justice; Human Rights

Cómo citar: Scocco, Marianela. (2020). "El intento de copamiento de La Tablada (1989). Represión, justicia y derechos humanos". Revista Historia Social y de las Mentalidades, 24(2), 121-148. DOI: $10.35588 /$ rhsm.v24i2.4460

\section{A MODO DE INTRODUCCIÓN. RECONSTRUCCIÓN HISTÓRICA DEL INTENTO DE COPAMIENTO DE LA TABLADA}

En la madrugada del 23 de enero de 1989 cuarenta y seis militantes de la agrupación Movimiento Todos por la Patria (MTP), con poca preparación militar, escasamente armados y encabezados por Enrique Gorriarán Merlo histórico dirigente del Partido Revolucionario de los Trabajadores-Ejército Revolucionario del Pueblo (PRT-ERP ${ }^{1}$ )-, intentaron copar los cuarteles del Regimiento de Infantería Mecanizada 3 (RIM 3) "General Belgrano"2 en la localidad argentina de La Tablada, partido de La Matanza (Buenos Aires). Tenían el supuesto propósito de frustrar un golpe militar carapintada en contra del gobierno de Raúl Alfonsín, quien había enfrentado tres levantamientos militares a lo largo de su gestión.

La serie de levantamientos militares llevados a cabo por oficiales que se denominaban "carapintadas" bajo la presidencia de Alfonsín fueron el de Semana Santa (1987), el de Monte Caseros (enero de 1988) y el de Villa Martelli (diciembre de 1988). Posteriormente ocurrió el del 3 de diciembre de 1990 bajo la presidencia de Carlos Menem. Los militares carapintadas pertenecían

1 El Partido Revolucionario de los Trabajadores (PRT) fue fundado en 1965 a partir de la fusión de dos agrupaciones políticas: el Frente Revolucionario Indoamericano Popular (FRIP) y Palabra Obrera (PO). En 1970 creó el Ejército Revolucionario del Pueblo (ERP) como su brazo armado. Hasta 1973 el ERP fue la principal organización guerrillera del país, por su capacidad operativa y la intensidad de su actividad de propaganda armada. Sobre el PRT-ERP ver Pozzi y Carnovale, Los combatientes.

2 El RIM 3 de La Tablada había sido un centro clandestino de detención en la última dictadura militar (1976-1983) pero además el personal militar del cuartel se había amotinado en apoyo al último levantamiento carapintada de diciembre de 1988. 
a un grupo dentro de la oficialidad de rango medio, integrado por algunos ex combatientes de la guerra de Malvinas (1982). Su identidad se definía en una oposición doble: al gobierno democrático que los perseguía y desprestigiaba, por un lado, y a las cúpulas militares, por su fracaso en defenderlos de esa "campaña de desprestigio" emprendida por el gobierno, por otro lado. Estas sublevaciones pusieron en jaque a la naciente democracia, a las posibilidades del gobierno y a la propia institución militar, al tiempo que evidenciaban los límites de la redefinición de las relaciones político-militares a través de la vía judicial. ${ }^{3}$ Sus reclamos se desprendían de la política de juzgamiento del gobierno de Alfonsín por los crímenes de lesa humanidad cometidos durante la última dictadura militar (1976-1983). El Juicio a las Juntas de 1985, que condenó a los comandantes de las tres primeras Juntas Militares de la dictadura, no fue una revisión general sobre todos los crímenes sino sobre una determinada cantidad de casos y delitos. Por tanto, el juicio pretendía distinguir niveles de responsabilidad para sancionar a los jefes máximos. Sin embargo, el artículo 30 de la sentencia amplió el círculo de responsables que serían juzgados, abriendo la posibilidad de continuar con los juicios. ${ }^{4}$ En términos generales, los carapintadas solicitaban el final de ese proceso de juzgamiento. ${ }^{5}$

En ese marco se produjo el intento de toma del cuartel La Tablada y su represión, que duró más de 30 horas. El fuego cruzado entre los asaltantes y las Fuerzas Armadas (FFAA) y de Seguridad se mantuvo durante todo el día 23 hasta que se interrumpió intermitentemente por la noche. Poco después de las 8 de la mañana del día 24, el general Alfredo Arrillaga, la máxima autoridad del cuartel, intimidó a los atacantes a rendirse. Estos respondieron que estaban dispuestos a hacerlo pero pidieron la presencia de un juez y atención médica para los heridos. Arrillaga aceptó esas condiciones y se inició el proceso de rendición. A las 9 comenzaron a salir de los lugares donde habían pasado la noche, el Casino de Suboficiales y la Compañía B. Todos caminaban hacia la Plaza de Armas, en donde fueron detenidos sin que ningún juez se hiciera presente. ${ }^{6}$

La represión al intento de copamiento fue desmedida y violenta y dejó varias personas muertas y heridas. Incluso luego de rendirse, varios

3 Sobre los levantamientos carapintadas ver Aboy Carlés; López; Canelo; y Saín

4 Sentencia Causa 13/84, Cámara Federal de Apelaciones de la Capital Federal, 9 de diciembre de 1985, p. 308.

5 Sobre la primera parte del proceso de juzgamiento penal de crímenes de lesa humanidad ver Aboy Carlés; Crenzel; Franco; Filippini.

6 Además de la bibliografía, para la reconstrucción de los hechos se tomó en cuenta el documental Tablada: el final de los '70 (2009) de Fabian Agosta, que reúne una importante cantidad de testimonios. https://www.youtube.com/watch?v=28PA-sSCXtk. 
combatientes fueron encapuchados y maniatados, algunos hasta ultimados allí y otros desaparecidos. Veintinueve muertos y trece detenidos fue la cifra oficial del saldo de la tentativa de copamiento. En sus Memorias Enrique Gorriarán Merlo afirmó que la cifra real era de treinta y dos muertos. ${ }^{7}$ Según denuncias del MTP, nueve prisioneros fueron asesinados tras su detención. Las ejecuciones y prácticas de tortura que se produjeron dentro del cuartel, así como las desapariciones de cuatro militantes (Iván Ruiz, José Díaz, Francisco Provenzano y Carlos Samojedny), guardaron cierta analogía con la metodología de terror de la última dictadura militar. La Comisión Interamericana de Derechos Humanos (CIDH) refrendó en su investigación a los nueve asesinatos. Trece fueron los cautivos en el RIM 3, a quienes se sumaron siete más, cinco detenidos y acusados de participar de los grupos de apoyo fuera del cuartel junto a Cintia Castro y Fray Antonio Puigjané, ${ }^{8}$ miembro de la dirección del MTP, quienes se presentaron espontáneamente y fueron apresados. Unos años después, el propio Gorriarán Merlo y su mujer, Ana María Sívori, se añadieron a esta lista. ${ }^{9}$ Entre las FFAA y de Seguridad hubo once muertos y treinta y ocho heridos según las cifras oficiales.

Desde el primer día, Gorriarán Merlo justificó la toma diciendo que tenía el objetivo de impedir un supuesto golpe de Estado (ataque preventivo) planeado por el entonces candidato a presidente Carlos Menem (luego presidente, entre 1989 y 1999) y el ex militar Mohamed Alí Seineldín. ${ }^{10}$ Para la investigadora sostiene que el problema de este último listado es que incluye el apodo de sosía de uno de los militantes caído durante el enfrentamiento, José "Chepe" Mendoza, cuya identidad falsa era "José Chebaia".

8 Antonio Puigjané se ordenó como sacerdote en Mar del Plata. En 1972, se fue expulsado por monseñor Plaza a La Rioja. Allí trabajó junto al obispo Angelelli hasta el golpe militar de 1976 y más tarde en la Villa Itatí de Quilmes. En la última dictadura militar acompañó a las Madres de Plaza de Mayo y encabezó marchas de familiares de detenidos desaparecidos. Posteriormente ingresó en el MTP. Falleció el 27 de agosto de 2019. (Anguita y Cecchini).

9 Por ese ataque, fueron detenidos Ana María Sívori en Rosario el 14 de septiembre de 1994 y Enrique Gorriarán Merlo en 1995 en México y extraditado hacia Argentina. En 1997, fueron condenados a 18 años de prisión y a prisión perpetua, respectivamente. Luego, protagonizaron junto a otros detenidos por La Tablada una huelga de hambre que duró 66 días. Fueron liberados en 2003 por un indulto presidencial del entonces presidente Eduardo Duhalde. Gorriarán Merlo falleció el 23 de septiembre de 2006 en el hospital Argerich de Buenos Aires, víctima de un paro cardíaco. Ver Gorriarán Merlo y Celesia y Waisberg.

10 Mohamed Alí Seineldín egresó del Colegio Militar en 1957 como integrante del Arma de Infantería del Ejército Argentino. Estuvo destinado en Tucumán durante el Operativo Independencia en 1975 y se hizo cargo de los grupos Halcón I y II, en Mendoza, ante la inminencia del conflicto con Chile, en 1978. La Cámara Federal de San Martín lo investigó por la desaparición de Antonio Giorgi, científico del Instituto Nacional de Tecnología Industrial, ocurrida el 27 de noviembre de 
Claudia Hilb, en cambio, un reducido grupo de personas encabezado por Gorriarán trató de fabricar un presente ficticio -el golpe carapintada- para erigir sobre esa ficción una mentira verosímil -fuimos a parar el golpe- que, bien instrumentada, hubiera podido "manipular" los sentimientos antigolpistas del pueblo en favor de la insurrección.

La Tablada es uno de los hechos más incómodos de la historia reciente argentina, motivo por el cual ha tenido menor representación en las memorias y en la historiografía. En la mayoría de los casos, fue inscripto en una línea de pensamiento acerca de la década del setenta y la violencia política. A través de un análisis sobre los textos que se refieren al tema, que oscilan entre trabajos de memoria, periodísticos y estudios académicos, este artículo se propone analizar las lecturas del ataque a La Tablada y el derrotero de la justicia al respecto, poniendo énfasis en las violaciones a los derechos humanos producidas, el rol del Estado, las consecuencias en la modificación de las leyes represivas y el cambio en la correlación de fuerzas en la relación gobiernos/FFAA en los últimos meses de la presidencia de Alfonsín y el nuevo gobierno de Menem.

En este sentido, el aporte que se espera hacer al tema busca insertarlo en una línea de investigación ya iniciada, desde una perspectiva teórico-metodológica orientada a los estudios de la represión y la violación a los derechos humanos en la historia reciente argentina. En esta línea, en contextos investigativos previos me ocupé tanto del accionar represivo de las FFAA y de Seguridad ("De los consejos"; "Las fuerzas represivas") así como de los movimientos sociales surgidos para reclamar frente a la violencia estatal en los años setenta y mediados de los ochenta (El viento sigue soplando; Una historia en movimiento). Extender esta línea de investigación para finales de los años ochenta y principios de los noventa es uno de los propósitos de este artículo, debido a que los análisis sobre los años del gobierno de Alfonsín post-86 han quedado reducidos a las "leyes de impunidad", sin ahondar en la complejidad de ese período. Para su análisis,

1978. Aunque nunca reconoció haber participado en ese episodio, declaró que había organizado la Unidad Especial Antisubversiva, que funcionó para el Mundial de Fútbol de 1978. Tras una reconocida participación en la Guerra de las Malvinas, fue agregado militar en Panamá, entre 1985 y 1987. Al regresar al país, en enero de 1987, fue designado jefe del Departamento III de Operaciones del II Cuerpo del Ejército en Rosario. El 4 de diciembre de 1988 lideró el alzamiento del cuartel militar de Villa Martelli. Estuvo detenido hasta 1989, cuando Menem lo indultó, al igual que a buena parte de los militares carapintadas que se habían alzado contra el gobierno de Alfonsín. A principios de 1990 inició giras por el país en defensa de los militares carapintadas. El gobierno dispuso otra vez su arresto y lo envió a la unidad militar de San Martín de los Andes, desde allí se responsabilizó del último levantamiento militar del 3 de diciembre de 1990. Fue dado de baja del Ejército el 2 de diciembre de 1993. 
además de los testimonios, la bibliografía y los artículos de la prensa disponibles; considero la articulación entre las disposiciones generales establecidas por leyes y decretos nacionales y, en menor medida, su aplicación judicial y penal, así como documentos de organizaciones internacionales, como la CIDH y Amnesty International (AI).

\section{BREVE REVISIÓN BIBLIOGRÁFICA}

El intento de copamiento a La Tablada ha sido poco estudiado por la historiografía argentina. Como suele suceder con la historia reciente, las narrativas provienen de tres lugares: unas del campo académico (Hilb; Carnovale, "La fundación del Movimiento"; "De Entre Todos"; Pontelli; Solis); otras del periodismo (Celesia y Waisberg; Montero) y otras del género testimonial (Ceresole; Mattini; Gorriarán Merlo; Alfonsín).

Algunos trabajos han puesto mayor énfasis en reconstruir la historia del MTP (Carnovale, "La fundación del Movimiento"; Montero) mientras que otros tienen como objetivo explicar el sentido que subyacía en las razones del MTP para llevar a cabo el copamiento de La Tablada (Hilb; Carnovale "De Entre Todos"). Un texto académico elaborado por el Grupo de Investigaciones sobre subjetividad social, área de conflicto y cambio social del Instituto de Investigaciones Gino Germani y publicado en la revista Lucha Armada (en el Anuario 2013), indagó a La Tablada como un acontecimiento que permite ser leído en tanto bisagra de nuevas modalidades de resistencia en contraste con las de los años setenta. Los periodistas Pablo Waisberg y Felipe Celesia, por su parte, realizaron una minuciosa investigación, consumando una reconstrucción exhaustiva no solo de los hechos ocurridos esos dos días, incluyendo la represión al asalto, sino también del derrotero anterior y posterior de los atacantes y del juicio realizado en 1989.

Pese a lo anterior, para este análisis nos interesan particularmente dos investigaciones recientes. Por un lado, Lorena Pontelli presenta un recorrido integral de la historia del ataque a La Tablada donde se preocupa tanto de rastrear los antecedentes del copamiento (los ocho intentos de copamientos consumados en Argentina entre 1973 y 1975) como de las consecuencias del ataque. Su hipótesis principal pone énfasis en la comprensión del período de transición democrática, atendiendo a las violaciones a los derechos humanos producidas a los militantes del MTP luego de rendirse, lo que hasta su estudio había sido poco atendido: 
Nuestra hipótesis es que, durante los días 23 y 24 de enero de 1989 en el RIM 3 de La Tablada, la consolidación de las normas de juego democrático se impuso por fuera de la ley, tanto por la razón como por la fuerza. La normalidad con la cual se aceptaron, legitimaron y silenciaron política y socialmente las desapariciones, ejecuciones sumarias y torturas nos advierten sobre la paradojal constitución de la “consolidación democrática (Pontelli 16).

Ana Carol Solis, por otro lado, también pone el foco en el uso de la violencia represiva respecto del operativo de recuperación del cuartel, pero desde los modos de inscripción pública y los discursos que la legitimaron y que predominaron en la prensa escrita. En un artículo de reciente publicación, Solis analiza las repercusiones, tomas de posición y acciones que generó el copamiento de La Tablada en el escenario nacional y, particularmente, en la ciudad de Córdoba, para luego dar lugar a algunos de los impactos que este acontecimiento implicó para ciertas militancias.

Por último, interesa resaltar que en los estudios clásicos centrados en el papel de las FFAA y en la construcción del control civil sobre ellas, la mayoría de los cuáles analizaron los levantamientos carapintadas (Soprano; Canelo; López; entre otros), no se haya ni una sola mención a los hechos de La Tablada de 1989 y sus consecuencias en dicha materia. Una excepción es la tesis doctoral de Marcelo Saín que hace una referencia al ataque del cuartel y sus consecuencias en este sentido, dentro de una serie de acontecimientos en las relaciones cívico-militares durante los gobiernos de Alfonsín y Menem. Tampoco existen referencias a estos hechos en la mayoría de la extensa bibliografía sobre el movimiento de derechos humanos y los procesos de justicia e impunidad sobre los crímenes de la dictadura militar. Una línea de estudios que incorporó -aunque brevemente- una referencia a La Tablada, se inserta en los estudios provenientes de las ciencias políticas que analizaron los cambios políticos producidos en la transición y los primeros gobiernos democráticos de la posdictadura, todos con un importante anclaje en la "revisión del pasado" y la política de justicia al respecto (Aboy Carlés; Acuña y Smulovitz; Massuco).

\section{LAS RAZONES DEL INTENTO DE COPAMIENTO}

No se puede realizar un análisis de las consecuencias del ataque sin un previo ensayo para comprender las razones que llevaron a los militantes de MTP a consumar esta acción. En este sentido, vale recordar que durante años 
la versión del MTP fue que irrumpieron en el cuartel para frenar un golpe carapintada en gestación. ${ }^{11}$ Gorriarán Merlo escribió en sus memorias que los oficiales panameños con quien él tenía contactos se habían infiltrado en el grupo de Seineldín y, de esta manera, la cúpula del MTP se enteró que los carapintadas proyectaban una nueva sublevación para enero de 1989 y cuyo propósito sería conseguir la renuncia de Alfonsín. Además, el líder del MTP aseguró que a mediados de enero supieron que el RIM 3 de La Tablada sería el epicentro de la rebelión, fundamentalmente porque esta era la unidad militar que reunía los vehículos mecanizados y se encontraba a una distancia relativamente corta de la capital. Gorriarán Merlo murió en el año 2006 sin desdecirse.

Cabe desatacar que el MTP no era técnicamente una guerrilla, si bien muchos de sus integrantes provenían de uno de los grupos que resultó de la división del PRT-ERP en el exilio: aquel liderado por Gorriarán Merlo. Hacia comienzos de 1979, este grupo decidió integrarse a la revolución sandinista en Nicaragua y participó tanto del triunfo contra la dictadura de Anastasio Somoza como de la construcción del nuevo gobierno revolucionario en dicho país. El fin de la dictadura militar argentina y la llamada reapertura democrática estimularon la creación por parte de este grupo de la revista Entre Todos. El corolario de esa iniciativa fue la fundación del MTP en 1986, que aspiraba a ser un movimiento político amplio e incluso participó de las elecciones de 1987 (Carnovale, "De Entre Todos"). Apenas tres años más tarde de su creación, el MTP intentó copar el cuartel militar de La Tablada.

Interesa recordar que el 12 de enero, antes del asalto, Jorge Baños, Francisco Provenzano, Roberto Felicetti y Antonio Puigjané, todos líderes del MTP, ${ }^{12}$ denunciaron en una conferencia de prensa que se estaba produciendo un complot golpista contra el gobierno democrático, liderado por el entonces candidato presidencial, Carlos Menem; el líder sindical, Lorenzo Miguel, y Seineldín, que había dirigido el tercer levantamiento carapintada desarrollado en diciembre de 1988. En esa ocasión, declararon que ambos líderes peronistas habían acordado con los militares producir un nuevo acto de sedición con el objetivo de devastar al presidente Alfonsín. ${ }^{13}$

A partir de estos datos conocidos popularmente en su momento, como sostiene Claudia Hilb, han surgido diversas hipótesis que desde entonces

11 El ejemplo más claro son los testimonios del documental ya citado Tablada: el final de los '70 (2009).

12 El primero y el segundo fueron asesinados en la toma del cuartel, el tercero fue detenido adentro y el cuarto fue apresado unos días después.

13 Clarín y Página/12, 13 de enero de 1989. 
intentaron explicar las causas del ataque. Una de ellas afirmó que el ingreso al cuartel del grupo del MTP podría haber resultado de una operación de inteligencia exitosa, "comprada" con cierta ingenuidad por Gorriarán Merlo y los suyos. Los militares habrían alimentado la versión de una conspiración para realizar un golpe de Estado e instigado la acción "preventiva" del MTP. El objetivo de tal operación habría sido desarticular un grupo ideológico opositor (el MTP), cuyo crecimiento veían con preocupación; cobrar cuentas pendientes a antiguos militantes del ERP -reverdeciendo la teoría del carácter agresor de la guerrilla en la represión de los setenta- y enaltecer el papel del Ejército en el mantenimiento de las instituciones frente al accionar renovado de la "subversión" $\mathrm{y}$, eventualmente, de los propios sectores carapintadas. Otra versión de esta hipótesis vendría de la instalación en el MTP de la información de un pacto entre Menem y Seineldín, con el fin de desprestigiar al líder peronista que se perfilaba ya entonces como ganador en las elecciones de fines de 1989.

Sin embargo, la hipótesis más fuerte sostuvo que el ataque se trató de la puesta en escena de un alzamiento y no de la convicción de que ese día se preparaba efectivamente una asonada militar en La Tablada. El éxito debía consistir en una insurrección exitosa, al estilo nicaragüense. ${ }^{14} \mathrm{El}$ ingreso al cuartel estuvo signado desde su preparación por la intención de fabricar un escenario ficticio de golpe carapintada, cuyo desenlace debía tomar ante los ojos de la sociedad el aspecto de la victoria de un grupo de jóvenes militantes populares que en su acción habrían logrado frenar un alzamiento contra la democracia.

No obstante, el plan quedó desenmascarado rápidamente. De inmediato circuló la información de que los militantes del MTP se habían dirigido al cuartel arrojando por el camino volantes de fabricación casera, firmados por un supuesto "Nuevo Ejército Argentino" y vivando a Rico y Seineldín, para "demostrar" la existencia del levantamiento militar. A pocos días del asalto, la idea del engaño ya estaba presente al menos en algunos dirigentes e intelectuales. Osvaldo Soriano expresaba esta idea en el diario Página 12: "Usaron el engaño como punto de partida para una supuesta sublevación popular y partieron de una falsedad histórica: atribuir a otros la responsabilidad de un crimen para usarlo, con disimulo, en provecho propio". (Página 12, 12 de febrero de 1989, en Pontelli 140). Algunos trabajos académicos que apoyaron esta hipótesis, sin embargo, no repararon en esta inmediatez de la idea del engaño.

14 La experiencia nicaragüense les había servido a los militantes del MTP para valorar el rol de los movimientos cristianos y la insurrección popular como camino a la revolución, en lugar del modelo de guerra popular y prolongada que había sostenido en sus orígenes el PRT-ERP. Para más información ver Carnovale, "De Entre Todos"; Celesia y Waisberg; y Montero. 
Hilb sugirió que algunos de los que participaron de la acción podrían haber sido víctimas del mismo engaño con el que la cúpula de la organización a la que pertenecían pretendió someter a la opinión pública. Pero aun engañados respecto de la connotación misma de la acción, esos militantes participaban de la idea de que el resultado de la detención de un golpe militar constituiría el movimiento inaugural que habría de culminar en una insurrección popular. Años más tarde del estudio de Hilb, los periodistas Waisberg y Celesia entrevistaron a cinco militantes del MTP partícipes del ataque y determinaron que un sector de sobrevivientes reconoció que crearon una mentira para poder montar la operación: la mentira era decir que fueron a frenar una conspiración carapintada, por eso hicieron una proclama, distribuida en falsos volantes dentro del cuartel, y una parte de ellos ingresaron vestidos de militares para generar la idea de que eran los mismos militares quienes atacaban.

Con el avance de las investigaciones y las causas judiciales, actualmente no hay dudas de que la acción se construyó sobre ese "engaño" y que tuvo como objetivo modificar las relaciones de poder. ${ }^{15}$ No obstante, para comprender ese "engaño" es necesario situarse en el contexto del año 1989 donde ya habían ocurrido sucesivas amenazas e intentos de golpes de Estado por el grupo de militares carapintadas en la Pascua de 1987, enero y diciembre de 1988. Los carapintadas tenían como principales demandas lograr la amnistía para aquellos que habían participado de la "lucha contra la subversión" y destituir al por entonces Jefe del Estado Mayor Conjunto, Héctor Ríos Ereñú, considerado por los rebeldes como un aliado del gobierno. También solicitaban el fin de la "campaña de desprestigio" llevada a cabo por los medios de comunicación y la no sanción a los sublevados. Los levantamientos carapintadas generaron un punto de inflexión en el MTP, que determinó el alejamiento de figuras importantes del movimiento, por un lado, y el viraje en la estrategia política y en los objetivos de la agrupación, por otro.

Como en el último levantamiento carapintada había ocurrido un gran enfrentamiento con manifestantes que salieron espontáneamente a defender la democracia, el MTP vio allí un estado de insurgencia y una voluntad de lucha que los entusiasmó en función de ir por un poco más: no sólo defender la democracia

15 Al cumplirse 30 años del ataque, el diario Infobae publicó una nota en la que la periodista Claudia Peiró sostenía que el 21 de enero de 2019, un familiar de un integrante del MTP anunció en una entrevista que el grupo emitirá un comunicado desmintiéndose a sí mismo: "Fueron a generar un hecho revolucionario a partir de una acción armada"; sería el nuevo relato de los sobrevivientes (Peiró). Al cierre de este artículo, tal comunicado no había sido emitido. 
sino generar alguna acción, con ese espíritu de lucha, que les diera iniciativa política y la oportunidad de condicionar al gobierno de Alfonsín.

Pero además esta situación se explica por la imposibilidad de algunos de estos militantes de regresar a la "vida corriente" luego del fracaso del proyecto revolucionario de quienes, aún jóvenes, habían sido parte de ese proyecto. Ajenos en su mayoría a los avatares de la vida cotidiana en Argentina durante la dictadura militar - por el exilio, la cárcel o la clandestinidad-, profesionalizados como militantes revolucionarios desde hacía décadas, los integrantes de aquel núcleo duro del MTP abrigaron las esperanzas de una reedición de la salida insurreccional en Argentina, sumidos en el microclima de la militancia revolucionaria y del triunfo reciente de la revolución nicaragüense (1979). Debido a esto se ha analizado este hecho como el último acto de la guerrilla argentina, en el sentido de enmarcarlo en una genealogía histórica que todavía tenía cierta lógica para estos militantes, aunque puede ser interpretada como anacrónica para la sociedad, ya que para el año 1989 ninguna organización argentina se inscribía en la lucha armada.

La pregunta no sería, entonces, cómo explicar la lógica que subyacía en la conducción del MTP al creer que era una acción viable realizar un copamiento en el año 1989, como han hecho algunas autoras (Hilb; Carnovale, "De Entre Todos"), "sino más bien (y previamente) cómo podríamos pensar la transición biográfica ${ }^{16}$ de quienes representaban a la izquierda argentina en la década del 80; cómo reflexionar sobre el paso de la revolución a la democracia, del combatiente al ciudadano" (Pontelli 71).

Ahora bien, como sostiene Montero, el problema ético-político que encierra La Tablada no es el del engaño como forma de hacer política (los falsos volantes ya se habían utilizado en el intento de copamiento de Monte Chingolo en 1975 con fines operativos) sino que el problema es el alegato sostenido durante el juicio y en los años posteriores, es decir, la falta de un discurso que le dé inteligibilidad y sentido a la acción. Esa falta de inteligibilidad y sentido produjo una serie de cuestionamientos sociales al ataque que operaron como marco explicativo para la justificación, aceptación o silenciamiento de las violaciones a los derechos humanos ocurridas tras el ataque, así como del endurecimiento de la legislación represiva.

16 Cabe destacar que, a partir del golpe de Estado del 24 de marzo de 1976, "la defensa de la democracia" empezó a ser la tarea para muchos ex militantes revolucionarios. La antinomia "democracia o golpe" nació para reemplazar a la vieja dicotomía setentista "revolución o golpe". 


\section{LA POLÍTICA DE ALFONSÍN Y EL DISCURSO PÚBLICO EN MATERIA DE JUSTICIA Y DERECHOS HUMANOS}

Para atender a una de las premisas principales de este artículo, acerca de que el extenso rechazo al asalto del cuartel explica -al menos en parte- la tolerancia social a la violencia estatal y la modificación de la legislación represiva a partir de ella, es necesario apuntar a un proceso más amplio de construcción de un "enemigo" que se inauguró en los primeros años setenta y continuó con la "teoría de los dos demonios".

Los orígenes de esta teoría, por lo general, suelen rastrearse en los años ochenta en el marco de la restitución democrática, donde a través de los decretos 157 y 158 Alfonsín ordenó enjuiciar a los siete jefes de las organizaciones armadas y a las tres primeras Juntas Militares de la dictadura, montando a partir de ello un manto de igualdad entre aquellos y estos últimos. En el primer decreto, se proponía la indagación de la violencia revolucionaria desde 1973 hasta 1983, mientras que el segundo se reducía a lo actuado por las FFAA a partir de 1976. De esta forma, se intentaba igualar los crímenes cometidos por la dictadura con las acciones llevadas a cabo por las organizaciones político-militares y se explicaba la violencia de Estado por la violencia revolucionaria (Crenzel). Las organizaciones guerrilleras se proponían como antecedente de la violencia estatal $\mathrm{y}$, de hecho, serían las únicas acusadas de la violencia previa al golpe de Estado, excluyendo las responsabilidades del gobierno de Isabel Martínez de Perón y los asesinatos de militantes políticos y sindicales, atribuidos generalmente a grupos paraestatales. Así, esta explicación del pasado de violencia de los años setenta como responsabilidad y resultado de dos violencias enfrentadas fue el tema fundamental en los primeros años de la posdictadura.

Sin embargo, como sostiene Marina Franco, dicha explicación no fue una construcción posdictatorial, sino que una explicación similar de la violencia como resultado de dos fuerzas enfrentadas que había estado instalada en el espacio público como clave de la conflictividad política de los años previos a la última dictadura militar. Entre 1973 y 1976 esta imagen de dos violencias, la extrema izquierda y la extrema derecha, era recurrente como manera de explicar los altos niveles de agresividad desatados por los comandos de derecha que estarían "respondiendo" a la de las organizaciones revolucionarias.

En los años ochenta el radicalismo fue el portador más visible de esta lectura binaria porque transformó esa visión en políticas de gobierno. Pero, si bien el objeto estaba puesto en que debía haber un castigo legal por las violaciones a los derechos humanos focalizado en el poder militar, se mantenía la equiparación de los demonios en términos de responsabilidad histórica y penal y 
la misma estructura lógica: el origen de la violencia por la "subversión". Aun así, el principal soporte de la "teoría de los dos demonios" no era una interpretación ofrecida solo por el alfonsinismo, sino la explicación naturalizada de la violencia del pasado que compartía una gran mayoría del arco político, y que tenía raigambre en la forma de percibir la experiencia del periodo 1973-76. Esto me interesa como explicación del rechazo que generó el intento de copamiento de La Tablada y que permitió la tolerancia de la violencia estatal. Franco advirtió sobre este punto cuando sostuvo que "el rol primigenio de causa y origen de la violencia adjudicado a las organizaciones armadas (...) es un factor explicativo esencial para entender el estigma posterior de la militancia en general" (26).

Por otro lado, además del origen de la violencia en el primer decreto, el decreto 158 proponía tres niveles de "víctimas" que habían sido objeto de la represión y que fueron enmarcadas por los militares bajo el rótulo de "subversión": "los verdaderos terroristas", los "meros disidentes" y "aquellos que se limitaban a criticar los métodos empleados" por la dictadura. ${ }^{17}$ Siguiendo a Franco, "se estaba suponiendo que una parte de las víctimas eran culpables de subversión (y/o su culpabilidad no había sido probada) (...) Así, las víctimas por las que se pedía justicia -los desaparecidos- eran, en su mayor parte, el demonio mismo y, además, primigenio: la subversión" (39). De esta forma, a quienes no formaban parte de las cúpulas guerrilleras se les otorgó el rol "legitimado" de víctimas. ${ }^{18}$ Algo similar se planteaba para la sociedad en general, que era presentada como ajena, inocente o víctima de esas violencias. ${ }^{19}$ La noción de "subversión" se instaló así como el "enemigo" percibido como amenaza del orden democrático.

Por eso, cuando los militantes del MTP atacaron el cuartel de La Tablada, las representaciones sociales acerca del "enemigo", que se habían cristalizado en esos enunciados y discursos públicos sobre la violencia política, se reactivaron para volver a instalar a ese "enemigo" en el "brote subversivo".

17 Argentina, Poder Ejecutivo Nacional, Decreto 158/83, 13 de Diciembre de 1983. Disponible en Memoria Abierta: http://memoriaabierta.org.ar/wp/wp-content/uploads/2018/06/Decreto-158. pdf.

18 Lo mismo ocurría con las cúpulas militares, que fueron juzgadas en el Juicio a las Juntas según el esquema de responsabilidad del alfonsinismo antes mencionado, otorgándole un rol de víctimas a los subordinados.

19 Para los otros componentes de la "teoría de los dos demonios" ver Franco; Cerruti; Scocco, "Reflexiones en torno". 


\section{LOS CUESTIONAMIENTOS}

Inmediatamente después de los sucesos, se produjo una ola de cuestionamientos, denuncias, descalificaciones, pedidos de retractación y distintas declaraciones que eran críticas con los hechos de La Tablada. El mismo día 23, las organizaciones de derechos humanos -Madres y Abuelas de Plaza de Mayo, Centro de Estudios Legales y Sociales (CELS), Asamblea Permanente por los Derechos Humanos (APDH), Familiares de Desaparecidos y Detenidos por Razones Políticas, Movimiento Ecuménico por los Derechos Humanos (MEDH) y Servicio de Paz y Justicia para América Latina (SERPAJ) ${ }^{20}$ - emitieron una declaración conjunta en la que condenaron enérgicamente "este nuevo ataque al orden constitucional" y, luego de exigir al gobierno "acceso a información veraz y completa para evitar manipulaciones que generan incertidumbre en el pueblo", llamaron la atención sobre la posibilidad de reinstalar "la lucha contra la subversión" y de militarizar la eventual salida del conflicto: "Alertamos contra los intentos de utilizar estos hechos para perseguir ideologías, impulsar la teoría de los dos demonios, reivindicar el terrorismo de Estado y achicar los espacios de pluralismo democrático conquistado por el pueblo argentino" (Página/12, 24 de enero de 1989, en Saín).

En cualquier caso, y al igual que lo que sucedió durante el levantamiento carapintada de la Semana Santa de 1987, el arco político y social en su conjunto rápidamente condenó el hecho, a lo que consideró un atentado contra el orden constitucional. Tales fueron esos cuestionamientos al ataque que los abogados de los organismos de derechos humanos evaluaron si debían defender o no a los detenidos. El MEDH decidió no representar a los militantes del MTP, planteando que no patrocinarían a los que tomaron las armas en democracia. En cambio, el CELS definió que sí participaría de la defensa pero representando a los jóvenes

20 El movimiento de derechos humanos en Argentina se constituyó en torno a la denuncias por las violaciones a los derechos humanos cometidos por la última dictadura militar (1976-1983). Algunos de los organismos que lo integran ya existían al momento de producirse el golpe de Estado; es el caso de la Liga Argentina por los Derechos del Hombre (LADH), la organización más antigua (1937); y otros que se habían creado en la coyuntura inmediatamente anterior, como el SERPAJ (1974); la APDH (1975) y el MEDH (1976). El resto de los organismos surge durante los años de la última dictadura porque estas organizaciones no lograron canalizar las demandas de los familiares directamente afectados por la represión, quienes formaron nuevos organismos, como Familiares de Detenidos y Desaparecidos por Razones Políticas (1976), Madres de Plaza de Mayo (1977) y Abuelas de Plaza de Mayo (1977). También se formó después del golpe de Estado el CELS, creado en el año 1979 por un grupo de abogados. Sobre estos organismos se creó una "narrativa clásica" que ocluyó la posibilidad de pensar sus variaciones regionales. Ver Alonso. 
y a los de bajos recursos y no a los dirigentes. Finalmente, se conformó un equipo de abogados que asistió a los trece detenidos dentro del cuartel y a los seis integrantes del grupo de agitación más el padre Antonio Puigjané (Celesia y Waisberg). El equipo estuvo coordinado por Eduardo Barcesat, abogado del Partido Comunista Argentino (PCA). Amnesty International (AI), por otro parte, apoyó solo la defensa de los "presos de conciencia", ${ }^{21}$ como Puigjané.

Al mismo tiempo, comenzaron a visibilizarse posiciones que alertaban sobre cómo este acontecimiento era útil a la radicalización de las derechas. En efecto, desde estas posiciones se denunciaban los peligros de un rebrote autoritario y, peor aún, del regreso al pasado cercano. En ese sentido, como afirma Solis:

los organismos de derechos humanos, a nivel nacional, se mostraron preocupados por la ola de rumores que pretendía vincularlos por la antigua participación de uno de los referentes del MTP-Jorge Baños, quien resultara muerto- en el CELS (...). Primero el CELS y luego el resto de los organismos hicieron declaraciones desligándose del hecho, pero fundamentalmente denunciando la ola de rumores que tenían por objeto deslegitimarlos a ellos y a sus luchas por supuestas conexiones con los militantes del MTP. (Solis 60)

Lo que de alguna forma quedó claro con el asalto a La Tablada es que ha significado el momento de la clausura de la resistencia de manera armada en Argentina. Sin embargo, como sostiene Pontelli (8), "si la acción armada del MTP fue generalizadamente repudiada e inasimilable para muchos sectores de la sociedad, se toleró públicamente la explícita violencia con la que el Ejército aplacó a los atacantes y recuperó el cuartel". Solis, por su parte, afirma que:

dos elementos fueron recurrentes en la discursividad de los repudios: 1) aseverar que se trataba de "un golpe a la democracia" conquistada en 1983 y 2) señalar solamente el dolor por la muerte de los últimos [militares y policías], pese a que el número de militantes muertos fue

21 Amnesty International (AI) es una organización no gubernamental con sede en el Reino Unido centrada en los derechos humanos fundada en 1961. AI define al preso de conciencia de la siguiente manera: "toda persona encarcelada o sometida a otras restricciones físicas por sus convicciones políticas, religiosas o cualquier otro motivo ideológico, o por su origen étnico, sexo, color, idioma, origen nacional o social, situación económica, nacimiento, orientación sexual u otras circunstancias, siempre que esa persona no haya recurrido a la violencia, ni propugnado su uso, o incitado al odio". Amnesty International (15). 
varias veces superior al de los uniformados, jerarquizando las muertes resultantes y, sobre todo, contribuyendo a relegitimar a las fuerzas armadas (y de seguridad) en el final de una década que los había tenido como protagonistas de una creciente amenaza de reversión autoritaria (...) Sus expresiones delimitaban claramente cuál(es) violencia(s) eran permitidas y la(s) que no lo eran. Es decir, la acción represiva como expresión del uso de la violencia estatal fue aceptada al mismo tiempo en que se deslegitimaba y rechazaba el uso de la violencia en manos de quienes no tenían esa condición estatal. (55)

De esta manera, coincido con las autoras en que esa represión legal e ilegal del Estado durante la recuperación del cuartel y las vejaciones sufridas los días siguientes por los detenidos del MTP fueron posibles gracias a los altos niveles de consenso alcanzados entre los distintos sectores políticos y sociales para repudiar al hecho y a sus ejecutores. Además, La Tablada fue el primer conflicto desde la reinstauración de la democracia en el cual la orden fue reprimir, a diferencia de los acontecimientos sucedidos por los alzamientos carapintadas, que solo fueron repelidos con violencia posteriormente bajo la presidencia de Menem.

En suma, dicha legitimidad para repudiar al copamiento se tradujo tanto en el Poder Ejecutivo como en el Poder Judicial, que obturaron las denuncias en torno a las violaciones a los derechos humanos sobre los militantes del MTP. En este sentido, distintas disposiciones del Estado allanaron el camino para una legislación cada vez más represiva que permitiera la intervención militar en los asuntos internos. Por último, la denuncia sobre la posibilidad de un "brote subversivo" como lo plantearon diferentes actores - desde Alfonsín al general Gassino $^{22}$-, también justificó la demanda militar a favor de una amnistía que beneficiara a los jefes militares procesados o condenados, al tiempo que renovó la solicitud de participación militar en "la lucha contra la subversión" como se había desarrollado en la década anterior, cuando se cometieron los atroces crímenes que dieron lugar a la revisión judicial iniciada en 1983.

\section{LA REPRESIÓN DESMEDIDA Y LAS VIOLACIONES A LOS DERECHOS HUMANOS}

No obstante la discusión de la época, considero que es necesario separar el ataque a un cuartel en plena democracia de los métodos criminales de las FFAA 
y de Seguridad y del ocultamiento y complicidad de los funcionarios del Poder Judicial. Para graficar la desproporción de la represión al ataque, cabe mencionar la versión que circuló acerca de los dichos del entonces comisario Juan Ángel Pirker, quien habría sostenido que para reducir a los atacantes hubiera alcanzado con utilizar gases lacrimógenos. ${ }^{23}$ Por otra parte, el ex oficial José Almada, que participó de la recuperación del regimiento desde adentro, señaló que "con hacer un cerco, con hostigarlos psicológicamente, cortarles los suministros, de alimentos, de agua y todo lo demás, bastaba" ${ }^{24}$ Como sostiene Saín, la dureza de la confrontación armada que tuvo lugar en La Tablada impidió, entre otras cosas, que se estableciera cualquier tipo de conexión con el grupo de asaltantes para averiguar sus reclamos y/o posición con respecto al hecho consumado.

La sentencia del fallo del juicio del 5 de octubre de 1989 estimó que el número de muertos del MTP que el Estado argentino reconoció eran veintinueve. Esto no coincidía con las denuncias de los militantes, que sostenían que eran treinta y dos los que no habían sobrevivido. Las inconsistencias surgieron debido a que en el listado oficial de muertos presentado el día 25 de enero no figuraban los nombres de Carlos Samojedny, que se habían entregado con vida, ni los de Alejandro Díaz e Iván Ruiz. Estos últimos habían sido fotografiados por Eduardo Longoni cuando escapaban del incendio de la Guardia de Prevención, la tarde del 23 de enero, desarmados y escoltados por un oficial. Para el Estado argentino, Iván Ruiz y José Díaz se habían fugado y por eso le ordenaron a Interpol su captura, mientras que el Poder Judicial afirmaba que no podía probarse que Samojedny haya estado en el cuartel. A su vez, los sobrevivientes denunciaron fusilamientos extra-legales, torturas y desapariciones que ocurrieron luego de que los militantes se rindieron y estuvieron desarmados. También los militantes apresados del "grupo de agitación" y quienes se presentaron voluntariamente ante las autoridades denunciaron torturas y apremios ilegales durante su detención. Sin embargo, estas denuncias no tuvieron eco en la justicia, fueron constantemente desalentadas por los jueces, que repitieron sin parar que no era materia de ese litigio y que ellos se encargaban de juzgar los delitos de los incursores y no de los

Los periodistas Darío Gallo y Gonzalo Álvarez Guerrero, en su libro sobre Enrique "Coti" Nosiglia, sostienen que en una reunión en la Casa de Gobierno, mientras el comisario Pirker, y el uno y dos del Ministerio del Interior, Nosiglia y Gil Lavedra, entre otros, miraban azorados por televisión el espectáculo trágico de cómo se bombardeaba un regimiento para sacar a un puñado de ocupantes, Pirker sentenció que: "Si me dan dos horas y una compañía con gases lacrimógenos, desalojo el regimiento". Los autores también destacan que Pirker murió días después, en medio de un ataque de asma, según la versión oficial.

24 Entrevista a José Almada en el programa radial El Reloj, FM Urbana 88.3, 04-11-2004. Transcripta y publicada en Periódico Tribuna, 25 de noviembre de 2004. Citada en Pontelli 126. 
militares y policías (Celesia y Waisberg; Pontelli). Como sostiene Pontelli, "No había discurso hospitalario para la "víctima culpable". Eran los desaparecidos culpables, los carbonizados culpables, los despedazados culpables, los fusilados culpables, para los cuales no había garantías constitucionales" (157). De esta manera, se reactivaba la noción de que las únicas "víctimas" que "merecían" justicia eran las "inocentes". Noción que fue instalada en la inmediata posdictadura y formó parte de la matriz de pensamiento de la "teoría de los dos demonios".

En el año 1997 la CIDH asumió las denuncias de los sobrevivientes y realizó una investigación con un posterior informe. Este informe probó que nueve personas habían sido ejecutadas de manera extrajudicial luego de rendirse. Sin embargo, partía de la presunción de que no había víctimas de desaparición forzada sino que, en realidad, había personas sin identificar, por el alto grado de carbonización de algunos cuerpos. ${ }^{25}$

Recién en 2013, el Equipo Argentino de Antropología Forense (EAAF) culminó con las tareas de identificación de los NN y la querella pudo afirmar con certezas que hay cuatro militantes del MTP que continúan desaparecidos: Francisco Provenzano, José Díaz, Carlos Samojedny e Iván Ruiz. Los testimonios de los sobrevivientes habían especificado cómo dos de ellos fueron capturados con vida antes de la rendición (José Díaz e Iván Ruiz) y los otros dos (Francisco Provenzano y Carlos Samojedny) fueron separados del grupo ya rendido en determinados momentos. Los dos primeros habían sido fotografiados por Eduardo Longoni cuando se entregaron con vida. Esto se diferencia de lo ocurrido en la última dictadura militar, donde hubo miles de personas desaparecidas pero no existen fotos que documenten cómo ocurría el hecho (Langland). El propio Longoni sostiene que "en Argentina no hay una sola foto de un secuestro, no hay fotos de los desaparecidos o de los prisioneros tirados de aviones de la Armada" (en Del Castillo Troncoso 103). En cambio, las fotografías de José Díaz e Iván Ruiz en el momento de su rendición demuestran que fueron detenidos con vida y por ello fueron utilizadas como prueba judicial para denunciar sus desapariciones, primero en la CIDH y luego en el juicio que comenzó en 2018. Siguiendo a Longoni, "Son las últimas fotos de esos dos guerrilleros dentro de un cuartel detenidos por oficiales del Ejército. Es terrible pensar que es la última imagen de dos personas a punto de desaparecer. Ya no en dictadura, sino en plena democracia" (en Del Castillo Troncoso 153). 


\section{LOS JUICIOS}

El primer juicio relacionado con los hechos de La Tablada se llevó a cabo ese mismo año y fue realizado en forma sumaria o abreviada, sin permitirles a los acusados apelar la sentencia, que es un principio básico del derecho. Esto fue posible porque en el juicio fue aplicada la Ley de Defensa de la Democracia, ${ }^{26}$ que se había sancionado en 1984, lo que agravó las penas e impidió que hubiera segunda instancia judicial. Dicha ley permitía condenar con penas de hasta 25 años de prisión a quienes se alzaran en armas contra la Constitución con el fin de cambiar el sistema de gobierno y a los funcionarios que colaboraran con gobiernos de facto. Solo fue aplicada en este juicio y para sancionar al Coronel Mohamed Alí Seineldín por uno de sus levantamientos. De esta manera, el tribunal que condenó a los presos de La Tablada bajo esta ley, se constituyó como un tribunal especial o ad hoc, en el sentido que fue creado para un fin determinado o pensado para una situación concreta.

Los enjuiciados por La Tablada fueron trece sobrevivientes más cinco militantes, a quienes los detuvo la policía en las afueras del cuartel, acusados de integrar el "grupo de agitación", y dos personas más (Cintia Castro y Fray Antonio Puigjané) que se presentaron voluntariamente ante las autoridades. Las características del juicio guardaron relación con los llevados a cabo por la Cámara Federal en lo Penal de la Nación (CFPN), creada el 28 de mayo de 1971 también mediante una ley (la $19.053^{27}$ ), aunque de un gobierno militar como era el de Alejandro Agustín Lanusse. Si bien no son procesos similares, la comparación es interesante para trazar una genealogía entre experiencias judiciales represivas, presentadas en ambos momentos como mecanismos "legales" que forman parte de procesos de institucionalización de la represión (Scocco, "De los consejos").

La CFPN era un tribunal judicial ad hoc para juzgar las "actividades extremistas" que buscaba brindar una cobertura de legalidad a la actividad represiva del Estado con mayor celeridad. Como el juicio de La Tablada, los juicios de la CFPN eran orales y sus resoluciones eran inapelables; es decir, no existía una doble instancia, esto es un tribunal superior al cual se pudiese recurrir

26 Argentina, Ministerio de Justicia y Derechos Humanos, Ley 23077 de Protección del Orden Constitucional y Defensa de la Democracia, 9 de Agosto de 1984, http://www.saij.gob. ar/23077-nacional-proteccion-orden-constitucional-vida-democratica-ley-defensa-democracialns0003417-1984-08-09/123456789-0abc-defg-g71-43000scanyel\#CT000.

27 Argentina, Ley 19.053, Justicia Nacional, Cámara Federal en lo Penal de la Nación, 28 de Mayo de 1971. http://servicios.infoleg.gob.ar/infolegInternet/anexos/105000-109999/105397/norma.htm 
en caso de considerar que algún derecho había sido violado (Sarrabayrouse Oliveira; Bacci et al.).

Otra característica del juicio de La Tablada que guardó similitud con los de la CFPN fue la estrategia de la defensa. Durante el juicio, esa estrategia se basó en el argumento alegado sobre la intención de frenar un golpe de Estado. La defensa de los acusados demandaba un relato unificado pero más aún necesitaba un motivo poderoso para justificar haber tomado las armas en democracia. Barcesat, el abogado que coordinaba la defensa, sostuvo que: "Convinimos que ellos iban a decir que fueron a parar un golpe carapintada. Era lo único que medianamente podía amortiguar el desprestigio al que sumieron a toda la izquierda. Ellos lo tomaron como verdad sabida, lo internalizaron como la gran explicación" (Celesia y Waisberg 245). A través de las audiencias se consolidó la teoría del "error esencial" que indicaba que los atacantes no pretendieron levantarse contra el gobierno sino que se habían equivocado en considerar la existencia de un golpe militar en marcha. La similitud con las estrategias de defensa que adoptaron los letrados de los presos políticos juzgados por la CFPN entre 1971 y 1973, la mayoría de ellos integrantes de las organizaciones político-militares de la época, se relacionaban explícitamente con los planteos expuestos por el abogado del Frente de Liberación Argelino, Jacques Vergés (1972), que conceptualizaba dos tipos de procedimientos a desplegar en los juicios por razones políticas: los de "connivencia" y los de "ruptura". La estrategia de "connivencia" partía de aceptar el ordenamiento normativo del "sistema" para, dentro de su marco legal, tratar de demostrar, o bien que el imputado no incurrió en el delito del que se lo acusaba, o bien que la figura delictiva creada por el "sistema" entraba en contradicción con los principios generales del derecho por él sustentados. La estrategia de "ruptura", por el contrario, tenía por objeto cuestionar la construcción "ficticia" de la Justicia, denunciando las condiciones en las que funcionaba el sistema jurídico, sus instituciones y actores (Chama; Bacci et al.). Como en aquella época, en el juicio de 1989 se estableció una combinación entre ambas estrategias. En esta dirección, los abogados de los presos por La Tablada tendieron a optar por una estrategia que trató de demostrar que la figura delictiva no era un alzamiento contra el gobierno sino el ejercicio del derecho a la rebelión para defender la democracia. Y, por otro lado, declararon que no existían garantías jurídicas mínimas y, por ende, que los acusados estaban "condenados de antemano", al tiempo que denunciaron las torturas sufridas en los lugares de detención, mostrando las condiciones en las que funcionaban las instituciones penitenciarias y sus actores. Pese al esfuerzo de la defensa, recibieron condenas desde la reclusión perpetua hasta once años de prisión.

Los varones fueron trasladados a la cárcel de Devoto $\mathrm{y}$, una vez terminado el juicio, a Caseros junto a las cinco mujeres que también habían sido condenadas, en donde estuvieron doce años presos. Durante ese tiempo 
mantuvieron distintas estrategias de lucha para conseguir conmutar las penas, como huelgas de hambre y solicitadas en los diarios. ${ }^{28}$ Por otro lado, estrecharon vínculos tanto con organismos de derechos humanos nacionales como con organizaciones internacionales, entre ellas, la CIDH y AI.

En los primeros días de enero de 2001, el Poder Ejecutivo decretó la conmutación de penas para los detenidos por La Tablada, con excepción de Sívori y Gorriarán Merlo, lo que significó la libertad inmediata de todos los conmutados. En mayo de 2003, el entonces presidente Eduardo Duhalde indultó a todos los condenados, hecho que determinó la libertad de los únicos que quedaban presos: Sívori y Gorriarán. Estos indultos fueron acompañados por otros a nueve militares carapintadas penados por actos de sedición contra el Estado democrático, entre los que se encontraba Seineldín.

El argumento alegado durante el juicio sobre la intención de frenar un golpe militar fue sostenido en los años posteriores. Aún resta responder por qué el MTP continuó manteniendo la primera versión que habían dado luego de la liberación de los presos. Recién a finales de 2018 comenzó el juicio por los crímenes de lesa humanidad cometidos en La Tablada tras la reapertura de las causas por estos delitos, con un único imputado, el ex General Alfredo Arrillaga, la máxima autoridad del cuartel cuando ocurrieron los hechos. El 12 de abril de 2019 el TOF 4 de San Martín, Buenos Aires, sentenció a cadena perpetua a Arrillaga por homicidio agravado contra José Díaz quien permanece desaparecido. En dicho juicio se logró desmontar la versión oficial, armada por el gobierno de Raúl Alfonsín y el Ejército, al comprobar que hubo delitos graves, ocultamiento y tergiversación de lo allí ocurrido en relación con las torturas, asesinatos y desapariciones cometidas contra los militantes del MTP en las acciones de recuperación del cuartel.

En un documento de la AFI (Agencia Federal de Informaciones, por aquel entonces Secretaría de Inteligencia del Estado-SIDE) sobre La Tablada, que el abogado querellante Pablo Llonto señaló en el alegato del juicio, se mencionaba el nombre de José Maradona Díaz y al lado tenía un número 2. Ese número 2 significaba abatido. Luego sostenía que hubo 27 abatidos y 4 NN. Más tarde, el 2 de febrero de 1989, colocaron entre los abatidos a Francisco Provenzano. Esos documentos reservados fueron pedidos durante el debate del juicio y quedaron a disposición de las partes ("Según la SIDE”).

28 Un importante trabajo de recopilación de notas periodísticas, volantes y solicitadas sobre el pedido de libertad y la realización de huelgas de hambre por los presos de La Tablada se encuentra en el Museo de la Memoria de Rosario. Carpeta "Recortes periodísticos sobre el copamiento del cuartel de La Tablada". 
El militar César Ariel Quiroga, quien se desempeñaba conduciendo una ambulancia dentro del cuartel, denunció que le hicieron firmar una declaración con hechos que él no vio. La versión oficial sostenía que José Díaz e Iván Ruiz habían sido capturados y subidos a la ambulancia que conducía Quiroga, quien se los entregó en custodia al suboficial Raúl Ricardo Esquivel en el RIM 3. El militar Jorge Eduardo Varando sostuvo hasta su muerte que Ruiz y Díaz huyeron del cuartel luego de matar a Esquivel. El abogado de Arrillaga esperaba que Quiroga ratificara la declaración que figura en el expediente, tomada en agosto de 1990, en el juzgado de Morón que dirigía Gerardo Larrambebere junto a la secretaría de este caso de Alberto Nisman. Pero la declaración inicial de Quiroga era opuesta a lo que le hicieron firmar. La abogada querellante Mazea dijo en el juicio: "El testimoniante primero sostuvo que no pasó lo que querían hacerle firmar, luego se van y el auditor del Ejército lo presiona para volver y que firme lo que se convertiría en la versión oficial" ("Se quebró un militar"). Aún queda pendiente conocer y juzgar lo ocurrido con las otras tres víctimas de desaparición no incluidas en este proceso: Iván Ruiz, Francisco Provenzano y Carlos Samojedny.

\section{LOS RESULTADOS Y SUS DERIVACIONES}

Las consecuencias directas del ataque a La Tablada fueron la modificación de las leyes represivas y el cambio en la correlación de fuerzas en la relación gobiernos/militares en las postrimerías de la presidencia de Alfonsín y los inicios de la de Menem. Esto fue posible debido a ese marco explicativo que justificó, o al menos silenció, las violaciones a los derechos humanos ocurridas tras el ataque y aceptó el endurecimiento de la legislación represiva, posibilitando una nueva configuración en la relación del gobierno y las FFAA. Como sostiene Saín:

a diferencia de lo expuesto por Alfonsín y el general Gassino, todo indicaba que no era un brote subversivo, sino una acción aislada llevada a cabo por un pequeño grupo de cuadros políticos sin entrenamiento.

Sin embargo, dicha justificación permitió una serie de medidas que consintieron a las FFAA volver a intervenir en la seguridad interior del Estado. Así, el 25 de enero - cuando no habían pasado ni 24 horas de la rendiciónAlfonsín instruyó, a través del decreto 82/89, al Fiscal General de la Nación para que "entregue las directivas necesarias para la investigación más rápida y efectiva" de los hechos. Mientras, promulgó el decreto 83/89 por el cual, dentro del alcance de la presidencia de la Nación, creó el Consejo de Seguridad 
Nacional -compuesto por los ministros del Interior, Defensa y Asuntos Exteriores y Culto, la SIDE, los jefes de las tres armas y del Estado Mayor Conjunto-con el fin de articular tareas de inteligencia interior. El Consejo de Seguridad iba en contra de la Ley 23.554 de Defensa Nacional ${ }^{29}$ aprobada meses antes, que instituía a las FFAA como instrumentos militares de defensa nacional ante la posible agresión militar de otro Estado y distinguía a la defensa nacional como un alcance funcional orgánico diferente de la seguridad interior y la intervención operativa y de inteligencia. Además, Alfonsín promulgó el decreto 327/89 que permitía la intervención de la inteligencia militar en los asuntos internos y envió al Congreso Nacional un proyecto de ley sobre terrorismo. ${ }^{30}$

En resumen, siguiendo a Saín, los decretos 83/89 y 327/89 violaron la Ley 23.554 al permitir la intervención militar en la seguridad interior. Sin embargo, dicha ley no fue derogada, lo que ciertamente, además de suponer una contradicción legal, expresó la intención oficial de responder positivamente, por un lado, a la queja militar a favor de su intervención en asuntos de seguridad interior y, por otro lado, a los partidos de oposición y a los sectores sociales que rechazaban la interferencia militar en estos asuntos.

Además, la opción de la violencia por el grupo atacante abrió la puerta para la reivindicación y legitimación del concepto de guerra que según las FFAA había caracterizado el contexto en el cual se dio la represión durante la dictadura militar (Acuña y Smulovitz). De esta forma, a poco más de un mes del último levantamiento carapintada, después de la recuperación del cuartel, los militares pasaron de ser la principal amenaza del gobierno a convertirse en su salvaguarda. Como sostiene Massuco, después de La Tablada, "la "victoria cultural" de la teoría de los dos demonios y de la guerra interna, y la "victoria política" de terminar con la revisión del terrorismo de Estado se concretaron" (120).

Comoresultado, los miembros de las FFAA entendieron que era el momento oportuno para presionar a favor de obtener una amplia amnistía que beneficiara al grupo de jefes uniformados y a los ex comandantes condenados. Hecho que se consumó con los indultos, los últimos concedidos tras el levantamiento carapintada del 3 de diciembre de 1990, bajo la presidencia de Menem. Los

29 Argentina, Ministerio de Justicia y Derechos Humanos, Ley 23554 de Defensa Nacional, 26 de abril de 1988, http://servicios.infoleg.gob.ar/infolegInternet/anexos/20000-24999/20988/texact.htm.

30 En sus memorias, Alfonsín afirma que el proyecto de Ley de Seguridad, que le daría un marco jurídico al Ministerio de Seguridad Interior, ya estaba siendo elaborado por el gobierno tiempo antes de que sucedan los hechos de La Tablada, por lo que el intento de copamiento habría servido más bien como excusa para el endurecimiento de la legislación represiva. 
indultos fueron una serie de diez decretos sancionados el 7 de octubre de 1989 y el 30 de diciembre de 1990 que condonaron las penas de civiles y militares involucrados en la represión de la dictadura militar, incluyendo a los miembros de las Juntas condenados en el Juicio de 1985. Esto alteró las relaciones políticomilitares, clausurando la sanción penal de los crímenes cometidos hasta finales de la década del noventa y más precisamente hasta los años dos mil para llevar a los responsables ante la justicia. ${ }^{31}$

\section{A MODO DE CIERRE}

El intento de copamiento del cuartel de La Tablada es uno de los hechos más incómodos de la historia reciente argentina, motivo por el cual ha sido relativamente poco estudiado. La mayoría de los escasos trabajos académicos y periodísticos que han abordado el tema se han preocupado por reconstruir los hechos y el ideario del MTP, inmersos en una línea de investigación sobre la década del setenta y la violencia política. No obstante, sigue existiendo un vacío en lo que respecta al análisis del rol que tuvo el Estado y en las consecuencias en la modificación de las leyes represivas y el cambio de la correlación de fuerzas en la relación gobiernos/ militares, con excepción de la tesis doctoral de Saín. Por su parte, Solis sostiene que uno de los efectos menos trabajados fue la rápida configuración de un escenario estigmatizador o de (re)estigmatización de las militancias, en parte como resultado de la actualización que el uso de la violencia evocaba, pero también como una descalificación más genérica a ciertas modalidades del compromiso político que fueron catalogadas de "subversivas" para volver a delimitar las fronteras entre las acciones políticas permitidas, toleradas y prohibidas.

Otro punto poco abordado fueron las derivas judiciales del caso. La aplicación de la Ley de Defensa de la Democracia en el juicio a los asaltantes de La Tablada, que agravaba las penas y prohibía la doble instancia judicial -como sucedió a principios de los años setenta con la CFPN-, significó un hecho al menos llamativo. Una ley que había sido creada con el espíritu de evitar nuevos golpes de Estado y dictaduras militares, fue aplicada por primera

31 A finales de los años noventa comenzó la reapertura de las causas por los delitos cometidos en la última dictadura militar, sobre todo aquellas referidas a la desaparición y apropiación de menores. En el año 2003 el Congreso Nacional derogó las Leyes del Perdón mediante la Ley 25.779/2003 y en 2005 una sentencia de la Corte Suprema de Justicia declaró la inconstitucionalidad de dichas leyes y ratificó la constitucionalidad de la Ley 25.779/2003. Esto permitió la reapertura de las causas por delitos de lesa humanidad cometidos durante la dictadura en todo el país. 
vez a un pequeño grupo de militantes políticos con escasa preparación militar que cometieron una acción aislada. Esto confirma la intención de reimpulsar la teoría de los dos demonios, reverdeciendo la hipótesis del carácter agresor de la guerrilla como en la violencia política de los setenta. Las estrategias de la defensa también guardaron similitud con la de los abogados de los presos políticos juzgados por la CFPN entre 1971 y 1973, tratando de demostrar que la figura delictiva no era un alzamiento contra el gobierno sino el ejercicio del derecho a la rebelión para defender la democracia y denunciando la inexistencia de garantías jurídicas mínimas y las torturas que habían sufrido los detenidos. Sin embargo, nada de esto fue escuchado, porque los cuestionamientos al ataque hicieron posible la justificación y tolerancia social de la represión, primero, y la ausencia de justicia, después. Hubo que esperar a la reapertura de las causas por los delitos de lesa humanidad cometidos en la última dictadura para juzgar, recién en 2019, a la máxima autoridad del cuartel cuando ocurrieron los hechos, el único imputado, ex General Alfredo Arrillaga.

Aun así, la consecuencia más importante del ataque -a mi modo de verfue el cambio en la correlación de fuerzas en el vínculo gobiernos/militares que quedó demostrada en la posibilidad otorgada a las FFAA de volver a intervenir en la seguridad interior del Estado - justificada en la denuncia sobre un supuesto "brote subversivo"- y en la obtención de los indultos. A través de un conjunto de medidas y decretos, se entró en contradicción, sin derogarla, con la Ley 23.554 de Defensa Nacional, sancionada el año anterior tras largos debates parlamentarios. De esta forma, en las postrimerías del gobierno de Alfonsín y a comienzos del de Menem, los militares volvieron a tener funciones en la seguridad interna, luego de haber sido juzgados y ampliamente cuestionados por su participación en la "lucha contra la subversión" durante la última dictadura. Finalmente, los indultos, que beneficiaron a los ex jefes militares y a los ex comandantes condenados, consumaron la impunidad y la amplia amnistía que venían intentando imponer los militares carapintadas a través de sus levantamientos.

\section{REFERENCIAS BIBLIOGRÁFICAS}

Aboy Carlés, Gerardo. Las dos fronteras de la democracia argentina. La reformulación de las identidades políticas de Alfonsín a Menem. Homo Sapiens, 2001.

Acuña, Carlos y Catalina Smulovitz. "Militares en la transición argentina: del gobierno a la subordinación constitucional". Historizar el pasado vivo en América Latina, directora Anne Pérotin-Dumon, 2007, pp. 1-94. http:// etica.uahurtado.cl/historizarelpasadovivo/es_contenido.php. 
Alfonsín, Raúl. Memoria Política. Fondo de Cultura Económica, 2003.

Alonso, Luciano. "El estudio de las luchas pro derechos humanos en Argentina: problemas de enfoque en torno a la categoría de movimiento social". Dilemas, apuestas y reflexiones teórico metodológicas para los abordajes en Historia Reciente, compiladora Patricia Flier, UNLP, 2014, pp. 56-83. Amnesty International. 30 años haciéndonos escuchar, 2008. https://www. es.amnesty.org/fileadmin/_migrated/content_uploads/30_aniversario.pdf Anguita, Eduardo y Daniel Cecchini. "Antonio Puigjané: los años en prisión y las misas en solitario que celebró en la pequeña celda 44 de Caseros", Infobae, 27 de agosto de 2019.

Bacci, Claudia, et al. Abogados, Derecho y Política. Memoria Abierta, 2010.

Canelo, Paula. "¿Qué hacer con las Fuerzas Armadas? Treinta años de cuestión militar en la Argentina". Observatorio Latinoamericano, 2013, pp. 136146. https://ri.conicet.gov.ar/bitstream/handle/11336/3902/CONICET_ Digital_Nro.5081_A.pdf? sequence $=5 \&$ isAllowed $=\mathrm{y}$.

Carnovale, Vera. "La fundación del Movimiento Todos por la Patria y la Revista Entre Todos". Ponencia, XIV Jornadas Interescuelas/Departamentos de Historia, 2013.

---. "De Entre Todos a La Tablada". Revista PolHis, año 6, no. 12, 2014, pp. 244-264.

---. Los combatientes. Historia del PRT-ERP. Siglo XXI, 2011.

Celesia, Felipe y Pablo Waisberg. La Tablada. A vencer o morir. La última batalla de la guerrilla argentina. Aguilar, 2013. https://doi.org/10.15446/achsc.v41n2.48790

Ceresole, Norberto. La Tablada y la hipótesis de guerra. Editorial del ILTRI, 1989.

Cerruti, Gabriela. "La historia de la memoria". Revista Puentes, no. 3, 2001, pp.14-25.

Chama, Mauricio. "La defensa de presos políticos a comienzos de los '70: ejercicio profesional, derecho y política". Cuadernos de antropología social, no. 32, 2010, pp. 195-217.

Crenzel, Emilio. La historia política del Nunca Más. La memoria de las desapariciones en la Argentina. Siglo XXI, 2008.

Del Castillo Troncoso, Alberto. Fotografia y Memoria. Conversaciones con Eduardo Longoni. Fondo de Cultura Económica, 2017.

Filippini, Leonardo. "La persecución penal en la búsqueda de justicia". Hacer justicia: nuevos debates sobre el juzgamiento de crímenes de lesa humanidad en Argentina, Centro de Estudios Legales y Sociales y Centro Internacional para la Justicia Transicional, Siglo XXI, 2011, pp. 19-48. 
Franco, Marina. "La 'teoría de los dos demonios' en la primera etapa de la posdictadura". Democracia, hora cero. Actores, políticas y debates en los inicios de la posdictadura, compiladoras Claudia Feld y Marina Franco, Fondo de Cultura Económica, 2015, pp. 23-80.

Gallo, Darío, y Osvaldo Álvarez Guerrero. El Coti. Biografia no autorizada de Enrique Nosiglia. Sudamericana, 2005.

Gorriarán Merlo, Enrique. Memorias de Enrique Gorriarán Merlo. De los setenta a La Tablada. Ed. Planeta, 2003.

Grupo de Investigaciones sobre subjetividad social, área de conflicto y cambio social. "La Tablada. Cierre y reconfiguración en los procesos de resistencia". Lucha Armada, Anuario 2013, pp. 177-186.

Hilb, Claudia. "La Tablada. El último acto de la guerrilla setentista". Lucha Armada, año 3, no. 9, 2007.

Langland, Victoria. "Fotografía y memoria". Escrituras, imágenes y escenarios ante la represión, compiladoras Elizabeth Jelin y Ana Longoni, Siglo XXI, 2005, pp. 87-91.

López, Ernesto. "Argentina: Un largo camino hacia el control civil sobre los militares". 2006. https://www.iugm.es/adefal/documentacion/nuevos analisis/ANALISIS\%20ARGENTINA.pdf

Massuco, Lucas. Transiciones argentinas. Política, ideología y juicios de lesa humanidad (1983-1995). Editorial Biblioteca, 2017.

Mattini, Luis. Hombres y mujeres del PRT-ERP. De Tucumán a La Tablada. Ed. de la Campana, 1996.

Montero, Hugo. De Nicaragua a La Tablada. Una historia del Movimiento Todos por la Patria. Peña Lillo/Ed. Del Continente, 2012.

"Murió Seineldín, el militar que desafió dos veces a la democracia", La Nación, 3 de septiembre de 2009.

Peiró, Claudia. "Por qué siguen mintiendo los asaltantes de La Tablada". Infobae, 23 de enero de 2019.

Pontelli, Lorena. "El intento de copamiento de La Tablada y la represión del Estado en el marco de la transición democrática (1989)". Tesis de licenciatura, UNR, 2018, https://rephip.unr.edu.ar/ handle/2133/13685? fbclid=IwAR3IlhBoGUpBi98qeocOxnso3j1Fn_ E0be7TDmH1m98yMFHSyFrlWVrn8Mg.

Pozzi, Pablo. Por las sendas argentinas. El PRT-ERP. La guerrilla marxista. Eudeba, 2001.

Saín, Marcelo. "Alfonsín, Menem e as relações cívico-militares. A construção do controle sobre as Forças Armadas na Argentina democrática (1983- 
1995)". Tesis de doctorado, Universidad Estatal de Campinas, 1999. http://www.resdal.org/Archivo/d000018a.htm.

Sarrabayrouse Oliveira, María José. "Familia judicial y dictaduras: la creación del 'fuero antisubversivo' en la década del 70”. Represión estatal y violencia paraestatal en la historia reciente argentina. Nuevos abordajes a 40 años del golpe de Estado, coordinadores Gabriela Águila et al., Facultad de Humanidades y Ciencias de la Educación Universidad Nacional de La Plata, 2016, pp. 269-294.

Scocco, Marianela. Una historia en Movimiento. Las luchas por los derechos humanos en Rosario (1968-1985). Colección Entre los libros de la Buena Memoria, Universidad Nacional de La Plata; Universidad Nacional de Misiones; Universidad Nacional de General Sarmiento. En prensa.

---. "Las fuerzas represivas y las divisiones de inteligencia. El Ejército y las policías en Rosario (1966-1979)". Estudios sobre Genocidio, año 10, vol. 14, 2019, pp. 11-28.

---. "De los consejos de guerra al Camarón. Respuestas represivas a las protestas sociales (1969-1973)". Anuario Escuela de Historia Virtual, vol. 10, no. 16, 2019, pp. 56-70. https://doi.org/10.31049/1853.7049.v10.n16.27244

---. "Reflexiones en torno a la teoría de los dos demonios en Argentina". Educación, Derechos Humanos y Memoria, Tomo III, compiladores Gabriel Cori, Mariana Della Bianca y otros, Secretaría de Derechos Humanos de la Provincia de Santa Fe, 2017, pp. 178-191.

---. El viento sigue soplando. Los orígenes de Madres de Plaza 25 de Mayo de Rosario (1977-1985). Último Recurso, 2016.

"Según la SIDE, José Maradona Díaz fue abatido". Diario del Juicio por los Desaparecidos de La Tablada, marzo de 2019.

"Se quebró un militar en el juicio por La Tablada y el exfiscal Nisman quedó involucrado". La izquierda diario, 14 de diciembre de 2018.

Solis, Ana Carol. "La Tablada en enero de 1989 y sus efectos e impacto en Córdoba. Sobre la (re) estigmatización de las militancias en la historia reciente". Anuario de la Escuela de Historia Virtual, año 10, no. 15, 2019, pp. 51-67. https://doi.org/10.31049/1853.7049.v0.n15.24515

Soprano, Germán. "Liderazgos militares en la transición democrática argentina".

Ponencia, IX Jornadas de Sociología de la Universidad Nacional de La Plata, 2016. http://sedici.unlp.edu.ar/handle/10915/74775

Velázquez Ramírez, Adrián. La democracia como mandato. Radicalismo y peronismo en los ochenta. Imago Mundi, 2019.

Vergés, Jacques. Estrategias judiciales en los procesos políticos. Editorial Anagrama, 1972. 